Bull. Chem. Soc. Ethiop. 2013, 27(3), 321-328.

Printed in Ethiopia

DOI: http://dx.doi.org/10.4314/bcse.v27i3.1

ISSN 1011-3924

(c) 2013 Chemical Society of Ethiopia

\title{
VOLTAMMETRIC DETERMINATION OF NICOTINE IN CIGARETTE TOBACCO AT ELECTROCHEMICALLY ACTIVATED GLASSY CARBON ELECTRODE
}

\author{
Hailemariam Kassa, Alemnew Geto ${ }^{*}$ and Shimelis Admassie \\ Department of Chemistry, Addis Ababa University, P.O. Box 1176, Addis Ababa, Ethiopia
}

(Received October 17, 2012; revised July 30, 2013)

\begin{abstract}
The electrochemical behavior of nicotine was investigated using cyclic and square wave voltammetric techniques. Electrochemical activation of glassy carbon electrode significantly increased the oxidation peak current of nicotine compared to the bare glassy carbon. At the activated glassy carbon electrode, the square wave voltammetry of nicotine revealed an oxidation peak at $+838 \mathrm{mV}$ ( $v s$. SCE) in phosphate buffer solution of $\mathrm{pH}$ 7. Under optimized conditions, the linear range $\left(\mathrm{R}^{2}=0.998\right)$ and detection limit $(3 \sigma)$ for nicotine determination were found to be $1-200 \mu \mathrm{M}$ and $0.7 \mu \mathrm{M}$, respectively. The method was successfully applied for the determination of nicotine in two brands of commercial cigarettes and acceptable recovery values of $97-108 \%$ were found.
\end{abstract}

KEY WORDS: Nicotine, Activated glassy carbon, Square wave voltammetry, Cigarette

\section{INTRODUCTION}

A great variety of solid electrodes have been employed in different voltammetric techniques over the years. Of the many different solid materials that can be used as working electrodes, the most commons are; carbon, platinum, and gold [1-3]. Carbon-based electrodes usually have a wider application than the other solid electrodes because of their broad potential window, low background current, rich surface chemistry, chemical inertness, low cost and suitability for various sensing and detection applications [4]. However, electron transfer rates observed at carbon surfaces are often slower than noble metal electrodes.

Glassy carbon electrode has been very popular because of its excellent electrical and mechanical properties, wide working potential range, extreme chemical inertness and relatively reproducible performance $[3,5]$. Additional activation steps, such as electrochemical, chemical, heat, or laser treatments have also been used to enhance the performance [3,6]. Among these, the electrochemical activation is considered a preferable and rapid in situ pretreatment technique [7].

Tobacco has been smoked for at least three thousand years. The frequent intake of nicotine leads to many potential effects on human health such as increased blood pressure and heart beat, atherosclerosis of the respiratory organs, and stimulation of the central nervous system leading to disruption of arteries and cardiovascular risk factors $[8,9]$. Smoking contributes heavily to the mortality burden because it is a major cause of vascular disease, cancer and chronic obstructive pulmonary disease [10].

It has been reported that over 4000 compounds exist in tobacco smoke with at least 50 known to be carcinogenic [11, 12] and more than 20 different alkaloids are found in tobacco and processed tobacco products [13]. Nicotine, (S)3-(1-methyl pyrrolidin-2-yl) pyridine (Scheme 1), is the most abundant of the volatile alkaloids in tobacco. Nicotine normally makes up about 5 percent by weight of a tobacco plant [14]. Cigarettes contain 8 to 25 milligrams (mg) of nicotine and approximately $1 \mathrm{mg}$ is absorbed in the human body [10, 15]. Despite the wellknown high toxicity of nicotine, recent studies suggested its therapeutic possibilities in some

*Corresponding author. E-mail: alemnew_geto@yahoo.com 
neurodegenerative diseases like Alzheimer's [16]. Therefore, reliable analysis of nicotine is important in medicine, toxicology, and tobacco industry [9].

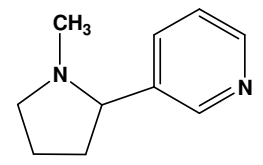

Scheme 1. Molecular structure of nicotine.

Several analytical techniques including high-performance liquid chromatography [15], gasliquid chromatography [17], solid-phase micro-extraction and gas chromatography/mass spectrometry [18] and spectrophotometry [19] have been reported for the analysis of nicotine. Most of these methods are very expensive and require lengthy purification steps as well as highly trained personnel to run the equipment. Although electrochemical methods overcome these shortcomings, the extremely high positive applied potential required for the oxidation of nicotine is one of the major problems for electrochemical determination. The electrochemcial oxidation of nicotine at $+1.3 \mathrm{~V}(v s . \mathrm{Ag} / \mathrm{AgCl})$ using a boron doped diamond electrode [20] illustrates this fact. Other approaches have used titanium dioxide polymer modified electrodes by a molecular imprinting technique [9] which involves a difficult polymer imprinting step. A pencil graphite based electrode has also been utilized for a voltammetric analysis of nicotine in the presence of anionic surfactant [10]. Among few studies involving nanotubes, carbon nanotube cluster modified screen printed electrode [11], and glassy carbon electrode modified with multi-walled carbon nanotube [21] and multi-walled carbon nanotubes-alumina-coated silica nanocomposite [22] were reported as electrochemical nicotine sensors. Recently, the electrochemical oxidation and its analytical determination of nicotine at a new conducting polymer modified electrode was demonstrated [23]. In this work a simple, sensitive and costeffective voltammetric method for the determination of nicotine in phosphate buffer solution was developed using activated glassy carbon electrode (AGCE). The developed method significantly reduced the over potential for nicotine oxidation which helps to reduce interference effects from co-existing compounds. It also offers the advantage of simple electrode preparation steps with no need to use chemical modifiers.

\section{EXPERIMENTAL}

\section{Materials and reagents}

Standard nicotine (98\%) was obtained from BDH Chemicals Ltd., England and stock solution of $50 \times 10^{-3} \mathrm{M}$ was prepared in distilled water and kept in a dark container. The stock solution was diluted with the appropriate buffer solution before use. Phosphate buffer solutions (PBS) $(0.1 \mathrm{M})$ were prepared using $\mathrm{K}_{2} \mathrm{HPO}_{4}$ and $\mathrm{KH}_{2} \mathrm{PO}_{4}$ (both from Fluka Chemika, Switzerland). The $\mathrm{pH}$ of the buffer solutions were measured using Jenway 3345 ion meter. Two brands of locally manufactured cigarettes were purchased from a local supermarket. Cyclic voltammetry (CV) and square wave voltammetry (SWV) were performed on a BAS-CV 50W voltammetric analyzer (Bioanalytical Systems Inc., USA). All experiments were conducted in a threeelectrode electrochemical cell with glassy carbon electrode (GCE) or activated glassy carbon electrode (AGCE) as the working electrode, saturated calomel electrode (SCE) as reference and platinum wire as the auxiliary electrode. 
Activation of the electrode

Prior to electrochemical activation, the GCE was polished with $1.0,0.3$ and $0.05 \mu \mathrm{M}$ alumina powder on polishing cloth and rinsed with distilled water. The clean electrode was then electrochemically activated by anodic oxidation at $+1.75 \mathrm{~V}$ for $200 \mathrm{~s}$ in phosphate buffer solution of $\mathrm{pH} 7$. The potential was then cycled between $+0.2 \mathrm{~V}$ and $+1.4 \mathrm{~V}$ at the scan rate of $100 \mathrm{mV} / \mathrm{s}$ until a steady state voltammogram was obtained. All cyclic and square wave voltammetric measurements were performed by running the potential from $+0.2 \mathrm{~V}$ to $+1.4 \mathrm{~V}$ under ambient conditions. The scan rate of the cyclic voltammetry was $100 \mathrm{mV} / \mathrm{s}$ while the optimized square wave voltammetric parameters were set at a frequency of $30 \mathrm{~Hz}$; pulse amplitude of $10 \mathrm{mV}$; and step potential of $60 \mathrm{mV}$.

\section{Sample preparation}

For the real sample analysis, two brands of locally produced cigarette products (Nyala and Delight from National Tobacco Enterprise, Ethiopia) were bought from a supermarket. Ten cigarettes were taken from each brand and the tobacco was collected separately and kept in an oven for $1 \mathrm{~h}$ at $45^{\circ} \mathrm{C}$. After the dried tobacco was ground using a mortar and pestle, a portion (1 g) of the powder was taken from each and dissolved in $10 \mathrm{~mL}$ of distilled water. The mixture was sonicated for $3 \mathrm{~h}$ in ultrasonic bath and filtered. Appropriate volume $(100 \mu \mathrm{L})$ of the clear filtrate was mixed with the phosphate buffer $(\mathrm{pH} \mathrm{7.0)}$ in $10 \mathrm{~mL}$ volumetric flask. Then, this mixture was analyzed under similar conditions as used to obtain the calibration graph. To make recovery measurements, previously analyzed cigarette samples were spiked with standard nicotine at three concentration levels of 10.0, 20.0 and $30.0 \mu \mathrm{M}$. The total nicotine content in the mixture was determined using the calibration curve.

\section{RESULTS AND DISCUSSION}

\section{Electrochemical behavior of nicotine}

Figure 1 displays the cyclic voltammetric responses of $1.0 \mathrm{mM}$ nicotine at bare glassy carbon electrode (GCE) and activated glassy carbon electrode (AGCE) in 0.1 M PBS of pH 7.0. At the bare GCE, the oxidation signal is poorly resolved and the peak is diffused over a broad potential region with a weak current response whereas, the oxidation of nicotine at the AGCE produced a well resolved peak at about $+0.92 \mathrm{~V}$ with a peak current of $2.78 \times 10^{-5}$ A. The significant enhancement in peak current response and a decrease in oxidation potential show the catalytic oxidation of nicotine at the AGCE. The absence of a peak on the reverse (cathodic) potential scan of the cyclic voltammetry shows the irreversibility of nicotine oxidation at both the activated and bare glassy carbon electrodes.

\section{Effect of buffer $\mathrm{pH}$}

The effect of buffer $\mathrm{pH}$ on the electrochemical behaviour of nicotine was investigated over the range of $\mathrm{pH}$ 5-9 and the results are depicted in Figure 2. Figure 3 shows the plots of resulting anodic peak currents and peak potentials as a function of $\mathrm{pH}$. Results show that the peak current increased with increasing solution $\mathrm{pH}$ until it reached a maximum at around $\mathrm{pH} 7.0$ and then declined. Therefore, $\mathrm{pH} 7.0$ was chosen as the optimum working buffer solution for subsequent measurements. 


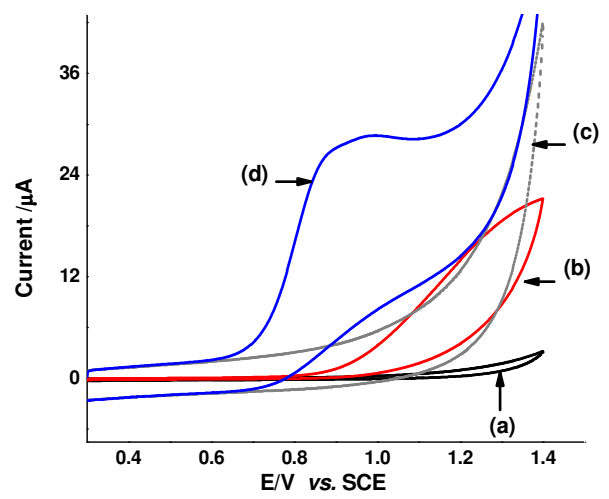

Figure 1. Cyclic voltammograms at bare GCE ( $a$ and b), and at AGCE (c and d), in the absence ( $\mathrm{a}$ and $\mathrm{c}$ ) and in the presence ( $\mathrm{b}$ and d) of $1.0 \mathrm{mM}$ nicotine in PBS of $\mathrm{pH} 7.0$ at 100 $\mathrm{mV} / \mathrm{s}$.

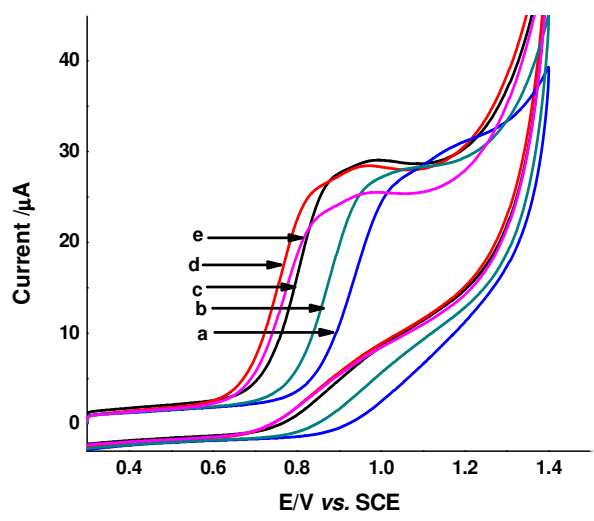

Figure 2. Cyclic voltammetric response (scan rate of $100 \mathrm{mV} / \mathrm{s}$ ) of $1.0 \mathrm{mM}$ nicotine at AGCE in phosphate buffer solutions of different pH: (a) 5.0; (b) 6.0; (c) 7.0; (d) 8.0; (e) 9.0.

As the $\mathrm{pH}$ of the solution increased, the peak potential shifted to lower positive potential indicating proton participation in the oxidation process. A plot of peak potential as a function of $\mathrm{pH}$ gave a straight line with a slope of $47 \mathrm{mV}$ and a correlation coefficient of 0.998 . This result indicates that the same number of protons and electrons are involved in the electrochemical reaction which is in agreement with previously proposed mechanism of nicotine oxidation (Scheme 2) [20, 21].

\section{Effect of potential scan rate}

The effect of potential scan rate on the oxidation of nicotine at AGCE was investigated by recording cyclic voltammograms of $1.0 \mathrm{mM}$ nicotine in $0.1 \mathrm{M}$ PBS (pH 7.0) at different scan rates (Figure 4). The peak current was proportional to the square root of scan rate in the range $10-500 \mathrm{mV} / \mathrm{s}$ with the equation:

$I_{p}(\mu A)-0.1395 v^{1 / 2}(m / / s)+2.87, R^{2}-0.9956$. 
This result suggests that the electrochemical behavior of nicotine at AGCE is mainly a diffusion-controlled process [24].

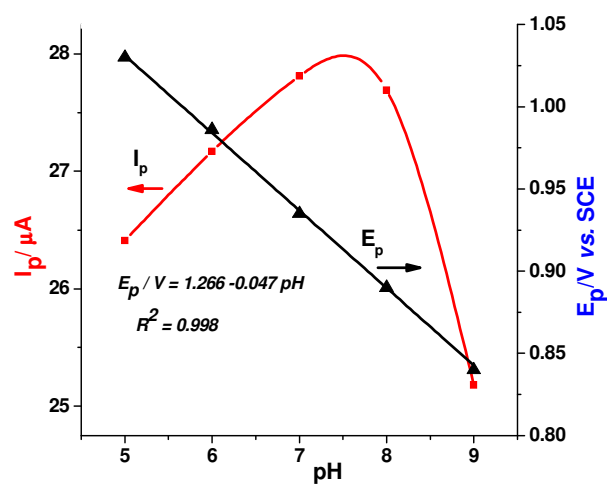

Figure 3. The effect of buffer $\mathrm{pH}$ on peak current and peak potential of $1.0 \mathrm{mM}$ nicotine at AGCE.<smiles></smiles>

Scheme 2. Electrochemical oxidation mechanism of nicotine.

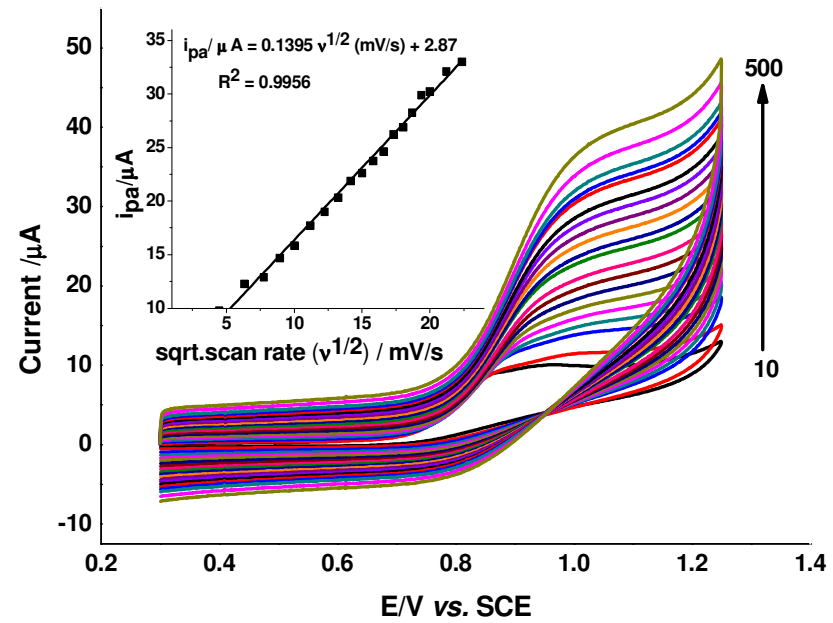

Figure 4. Cyclic voltammograms of $1.0 \mathrm{mM}$ nicotine at different scan rates $(10-500 \mathrm{mV} / \mathrm{s})$ at AGCE in $\mathrm{pH} 7.0$ phosphate buffer solution. Inset: Plot of anodic peak current as a function of square root of scan rate. 


\section{Calibration curve}

Square wave voltammetry was selected for the analytical determination of nicotine due to its high sensitivity and better peak resolution compared to cyclic voltammetry. To evaluate this feature, measurement parameters were optimized and a calibration curve was constructed. Figure 5 shows the square wave voltammograms obtained for different concentrations of nicotine in the range from 1-200 $\mu \mathrm{M}$ and the linear dependence of the peak currents with the concentration of the analyte.

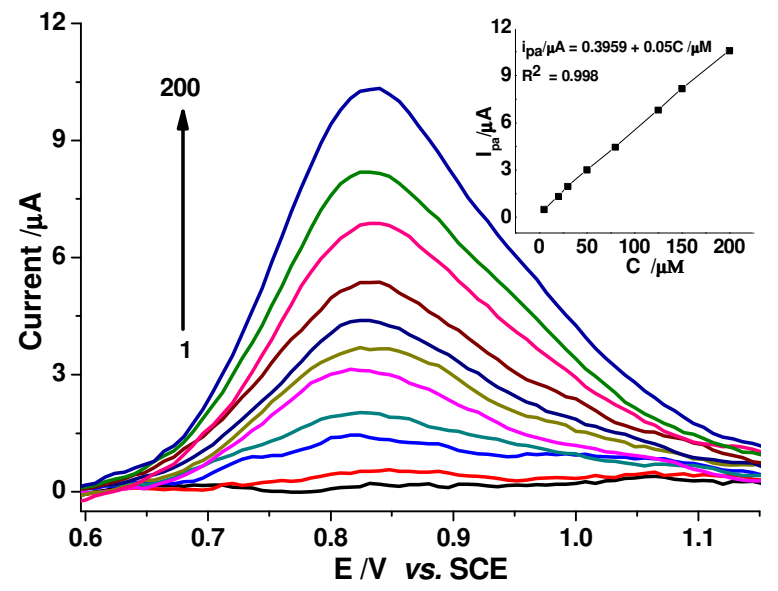

Figure 5. Square wave voltammograms obtained for different concentrations of nicotine: 1, 5, $20,30,50,60,70,100,125,150$, and $200 \mu \mathrm{M}$. Inset: Plot of the oxidation peak current against concentration of nicotine.

The peak current at $+0.83 \mathrm{~V}$ increased linearly with nicotine concentration with a linear regression equation $i_{p a}(\mu \mathrm{A})=0.3959+0.05 C(\mu M)\left(R^{2}=0.998\right)$. The calculated $(3 \sigma, n=6)$ limit of detection for nicotine was $0.7 \mu \mathrm{M}$, which is lower than previously reported values obtained at different modified electrodes (Table 1).

Table 1. Comparison of the analytical performance results of some methods for the determination of nicotine.

\begin{tabular}{|l|c|c|c|}
\hline Analytical method & Linear range/ $\mu \mathrm{M}$ & $\mathrm{LoD} / \mu \mathrm{M}$ & Reference \\
\hline Spectrophotometric & $0.62-46.24$ & 0.5 & {$[19]$} \\
\hline LC-MS-MS & $0.25-24.66$ & - & {$[14]$} \\
\hline MWCNT-ACS-GCE/Amperometry & $0-1500$ & 1.4 & {$[22]$} \\
\hline PGE/SWV & $7.6-107.5$ & 2 & {$[10]$} \\
\hline $\mathrm{CNT}-\mathrm{GCE} / \mathrm{CV}$ & $10-1000$ & 2 & {$[11]$} \\
\hline $\mathrm{BDD} / \mathrm{SWV}$ & $5-500$ & 3.1 & {$[20]$} \\
\hline $\mathrm{TiO}_{2}$-MIP-PEDOT/Amperometry & $0-5000$ & 4.9 & {$[9]$} \\
\hline MWCNT-GCE/DPV & $31-1,900$ & 9.3 & {$[21]$} \\
\hline p-(AHNSA)-GCE/SWV & $1-200$ & 0.9 & {$[23]$} \\
\hline AGCE/SWV & $1-200$ & 0.7 & This work \\
\hline
\end{tabular}


Sample analysis, recovery and interference studies

The method was successfully applied for the determination of nicotine in two brands of locally manufactured cigarette products: Delight and Nyala. The results obtained by triplicate measurements with freshly prepared electrodes are shown in (Table 2). Comparison of the experimental values with the actual content of nicotine in the samples analyzed could not be made since the samples did not have a label claimed value. However, the results obtained are in the range where nicotine is typically available in tobacco leaves which is $2-8 \%$ of the dry weight [23]. The reliability of the method was also checked by recovery experiments under the optimized conditions by spiking known amounts of nicotine standard solutions to the previously analyzed cigarette samples. Recoveries (see Table 3 ) were $97-108 \%$ suggesting that the method couldbe applied to the determination of nicotine in real samples.

Table 2. Nicotine content in two cigarette tobacco samples determined by SWV at AGCE.

\begin{tabular}{|c|c|c|}
\hline Cigarette & ${ }^{\mathrm{a}}$ Nicotine content $(\% \mathrm{w} / \mathrm{w})$ & $\%$ RSD \\
\hline Nyala & 2.54 & 0.5 \\
\hline Delight & 2.04 & 0.94 \\
\hline
\end{tabular}

average of three measurements.

Table 3. Nicotine recovery experiments in cigarette tobacco samples.

\begin{tabular}{|c|c|c|c|c|c|c|}
\hline Nicotine & \multicolumn{3}{|c|}{ Nyala } & \multicolumn{3}{c|}{ Delight } \\
\cline { 2 - 7 } Added/ $\mu \mathrm{M}$ & ${ }^{\mathrm{b}}$ Found/ $\mu \mathrm{M}$ & \%Recovery & \%RSD & ${ }^{\mathrm{b}}$ Found/ $\mu \mathrm{M}$ & \% Recovery & \% RSD \\
\hline 10.0 & 10.3 & 103 & 0.46 & 9.7 & 97.0 & 0.60 \\
\hline 20.0 & 19.9 & 99.5 & 0.43 & 19.8 & 98.5 & 0.65 \\
\hline 30.0 & 30.3 & 101 & 0.20 & 32 & 108 & 0.68 \\
\hline
\end{tabular}

baverage of three measurements.

In this study, the effect of interference from some foreign species, such as $\mathrm{Cu}^{+2}, \mathrm{Fe}^{+3}$, pyridine, acetic acid and glucose for the determination of $100 \mu \mathrm{M}$ nicotine were examined using SWV. Selection of these species was based on their common availability in the environmental and plant samples except for pyridine due to its structural similarity to nicotine. The presence of equimolar amounts of acetic acid and $\mathrm{Cu}^{+2}$ produced interference that can affect the accuracy of nicotine determination, while100-fold higher levels of $\mathrm{Fe}^{+3}$, pyridine and glucose showed no interfere. The interference from other alkaloids, which could be present in tobacco, was not studied because their relative low concentration, $0.2-0.5 \%$ of total alkaloids [25], was presumed to have insignificant influence on the voltammetric determination of nicotine.

\section{CONCLUSION}

This report demonstrated that the electrochemical activation of glassy carbon electrode significantly reduced the over potential for the oxidation of nicotine and produced an enhanced oxidation current response. Under optimized conditions of square wave voltammetry, the developed method gave low detection limit, wide linear range, and acceptable recovery for the detection of nicotine. The method was successfully applied to the detection of nicotine in cigarette tobacco samples. 


\section{REFERENCES}

1. Brett, C.M.A.; Brett, A.O. Electrochemistry Principles: Methods and Applications, Oxford University Press Inc: New York; 1993.

2. Christensen, P.A.; Hamnett, A. Techniques and Mechanisms in Electrochemistry, Chapman and Hall: India; 1994.

3. Wang, J. Analytical Electrochemistry, 3rd ed., John Wiley and Sons: New York; 2006.

4. Uslu, B.; Ozkan, S.A. Comb. Chem. High Throughput Screen 2007, 10, 495.

5. Vettorazzi, N.; Otero, L.; Silber, J.J.; Sereno, L. J. Braz. Chem. Soc. 1994, 5, 155.

6. Uslu, B.; Ozkan, S.A. Anal. Lett. 2007, 40, 817.

7. Shi, K.; Hu, K.; Wang, S.; Laub, C.Y.; Shiu, K.K. Electrochim. Acta 2007, 52, 5907.

8. Wang, L.; Xiong, H.; Zhang, X.; Wang, S. Electrochem. Commun. 2009, 11, 2129.

9. Wu, C.T.; Chen, P.Y.; Chen, J.G.; Suryanarayanan, V.; Ho, K.C. Anal.Chim. Acta 2009, $633,119$.

10. Levent, A.; Yardim, Y.; Senturk, Z. Electrochim. Acta 2009, 55, 190.

11. Highton, L.; Kadara, R.O.; Jenkinson, N.; Riehl, B.L.; Banks, C.E. Electroanalysis 2009, 21, 2387.

12. Wang, S.N.; Xu, P.; Tang, H.Z.; Meng, J.; Liu, X.L.; Huang, J.; Chen, H.; Du, Y.; Blankespoor, H.D. Biotechnol. Lett. 2004, 26, 1493.

13. Kataoka, H.; Inoue, R.; Yagi, K.; Saito, K. J. Pharm. Biomed. Anal. 2009, 49, 108.

14. Vlase, L.; Filip, L.; Mindrutau, I.; Leucuta, S.E. Studia Universitatis Babes-Bolyai, Physica, L. 2005, 4b, 19.

15. Byrd, G.D.; Davis, R.A.; Ogden, M.W. J. Chromatogr. Sci. 2005, 43, 133.

16. Picciotto, M.R.; Zoli, M. Front. Biosci. 2008, 13, 492.

17. Hengen, N.; Hengen, M. Clin. Chem. 1978, 24, 50.

18. Wu, W.; Ashley, D.L.; Watson, C.H. Anal. Chem. 2002, 74, 4878.

19. Al-Tamrah, S.A. Anal. Chim. Acta 1999, 379, 75.

20. Suffredini, H.B.; Santos, M.C.; De Souza, D.; Codognoto, L.; Homem-de-Mello, P.; Honorio, K.M.; da Silva, A.B.F.; Machado, S.A.S.; Avaca, L.A. Anal. Lett. 2005, 38, 1587.

21. Xiong, H.; Zhao, Y.; Liu, P.; Zhang, X.; Wang, S. Microchim. Acta 2010, 168, 31.

22. Wang, S.J.; Liaw, H.W.; Tsai, Y.C. Electrochem. Commun. 2009, 11, 733.

23. Geto, A.; Amare, M.; Tessema, M.; Admassie, S. Electroanalysis 2012, 24, 659.

24. Liu, S.Q.; Sun, W.H.; Li, L.C.; Li, H.; Wang, X.L. Int. J. Electrochem. Sci. 2012, 7, 324.

25. Garrigues, J.M.; Ponce, A.P.; Garrigues, S.; de la Guardia, M. Anal. Chim. Acta 1998, 373, 63. 